\title{
TRANSFORMACIONES DEL BOSQUE EL OLIVAR: LA RUTA HACIA LA CONSERVACIÓN DEL PAISAJE
}

\author{
TRANSFORMATIONS OF EL OLIVAR FOREST: \\ THE WAY TOWARD LANDSCAPE CONSERVATION
}

\author{
MARINO RUIZ \\ Universidad Nacional de Ingeniería \\ orcid.org/0000-0001-8469-9979
}

\begin{abstract}
El paisaje urbano es el componente territorial de las ciudades, ligado al componente humano que lo percibe y le da el valor correspondiente. El bosque El Olivar de San Isidro, espacio público emblemático de la ciudad de Lima, sobresale por sus cualidades paisajísticas que no han sido valoradas más allá de su mera importancia estética. En el siguiente artículo se muestran las constantes transformaciones por las que ha pasado, vinculadas a la percepción del paisaje urbano, el uso del bosque y la ocupación del lugar, ocurridas durante el proceso de expansión urbana de Lima. La importancia del bosque El Olivar va más allá de la simple percepción estética del usuario: radica en la relación forjada a través del tiempo entre el paisaje y la ciudad, $\mathrm{y}$ en las reflexiones que podemos realizar en torno a dicha relación. El viejo bosque de olivos nos brinda ahora la oportunidad de repensar nuestra posición en torno a su valor paisajístico tanto para los usuarios como para la ciudad en su conjunto; de este modo, podremos identificar las acciones que permitan protegerlo y conservarlo. Dicha conservación permite lograr un equilibrio adecuado entre naturaleza y ciudadanía, razón de ser de un entorno urbano sostenible.
\end{abstract}

bosque El Olivar, percepción del paisaje, paisaje cultural, paisaje urbano, sostenibilidad
MANUEL PALOMINO

Universidad Nacional de Ingeniería

orcid.org/0000-0002-5531-8249

Recibido: 30 de junio del 2020

Aprobado: 18 de enero del 2021

doi: https://doi.org/10.26439/limaq2021.n007.5181

Urban landscape is the territorial component of cities, which is linked to the human component that perceives and values it accordingly. El Olivar Forest of San Isidro district, an emblematic public space in the city of Lima, stands out for its landscape qualities, which have not been valued beyond its mere aesthetic importance. This article shows the constant transformations it has undergone, which are related to the perception of the urban landscape, the use of the forest and the occupation of the place that occurred during the urban expansion of Lima. The importance of El Olivar Forest goes beyond the simple aesthetic perception of the user: it consists in the relationship built through time between landscape and city, and in the reflections around this relationship. The old olive grove forest offers us nowadays the opportunity to rethink our position regarding its landscape value, both for users and for the city as a whole. Thus, we will be able to identify the actions that will allow its protection and conservation. Such conservation enables us to achieve an adequate balance between nature and citizenship, the raison d'être of a sustainable urban environment.

El Olivar Forest, perception of the landscape, cultural landscape, urban landscape, sustainability 


\section{INTRODUCCIÓN}

El bosque El Olivar, ubicado en el distrito de San Isidro, es uno de los espacios públicos más concurridos y representativos del paisaje urbano de la ciudad de Lima, erigiéndose como una buena muestra de pertinencia espacial y estética, en un contexto recurrente de abandono de los espacios públicos y de falta de integración con la ciudad, así como por su valor patrimonial excepcional como centenario testigo de las vicisitudes del asentamiento humano en el valle del Rímac a lo largo de los siglos. Por lo tanto, se muestra el proceso de crecimiento y desarrollo del bosque El Olivar vinculando una serie de factores y acontecimientos que han sido determinantes para el paisaje urbano resultante, así como para su integración en la trama urbana de Lima.

El objetivo del presente trabajo es evidenciar cómo, a lo largo del tiempo, las transformaciones del paisaje debido a la acción del hombre han llevado a la degradación del objeto de estudio y cómo, por medio de diversas acciones, dicho paisaje urbano puede recuperar su importancia primigenia.

El trabajo es un estudio de caso y consta de cinco partes; primeramente, una parte teórica donde se exponen los conceptos de percepción del paisaje desde un enfoque estético, de paisaje urbano, de patrimonio, de conservación y de su sostenibilidad, con énfasis, finalmente, en la capacidad de cambio del paisaje. Posteriormente, se organizan los hechos históricos más relevantes conforme a los conceptos expuestos en los capítulos anteriores y se trazan las etapas de transformaciones del bosque El Olivar. Luego, se desarrollan algunas reflexiones a partir de la comparación de los hechos mostrados en la línea de tiempo y los resultados comparativos de los indicadores. Finalmente, se exponen las conclusiones con base en lo desarrollado a lo largo del trabajo a fin de invitar a la reflexión en torno a los paisajes de nuestra ciudad y su interacción con el componente humano.

\section{OBJETIVO Y METODOLOGÍA}

El objetivo del presente estudio es determinar las características y los valores del paisaje en el bosque El Olivar, los cambios en su uso y rol preponderante a lo largo del tiempo y las causas que determinan dichos cambios a partir de una mirada retrospectiva en torno a la historia y a la cantidad de olivos que han poblado este singular espacio limeño.

La metodología comprende dos momentos diferenciados. El primero consiste en la revisión de la teoría sobre el concepto de paisaje: su definición, percepción, clasificación y conservación. Si bien no existe una teoría unificada sobre dicho concepto, la visión crítica y complementaria de diversos autores y de los dispositivos internacionales vigentes resulta enriquecedora para nuestro objetivo, es decir, la comprensión de las causas y efectos de los cambios operados en el viejo bosque de olivos a lo largo de su existencia. 
El segundo momento comprende la recopilación de información documental de diversas fuentes que nos permitan reconstruir la historia del olivar, a través de la revisión bibliográfica de planes de desarrollo urbano de la Municipalidad de San Isidro, bases de datos históricas, normativa local específica de este territorio y repositorios digitales relevantes. Establecida la cronología de nuestro espacio de estudio, la información fue procesada en torno a las variables y a la línea de tiempo establecidas. Para ello se utilizaron programas como Microsoft Office para la edición de textos y tablas, y Adobe, para la elaboración de gráficas. Finalmente, del análisis de resultados derivan las conclusiones expuestas.

Una limitación del trabajo fue la desestimación por parte de la gestión actual del plan urbano actualizado por la gestión 2015-2018. La esperada aplicación de dicho instrumento no se llevó a cabo, por lo que no se incluyen los resultados de dicha experiencia, solo se toma como referencia documental al citado plan.

\section{MARCO TEÓRICO}

\section{El paisaje y su percepción}

¿Qué es el paisaje? El Convenio Europeo del Paisaje (2000), elaborado por el Consejo de Europa, define claramente al paisaje como "cualquier parte del territorio tal como la percibe la población, cuyo carácter sea el resultado de la acción y la interacción de factores naturales y/o humanos" (p. 2). Lo importante de esta definición es que señala tres factores fundamentales para la existencia del paisaje: una parte del territorio plenamente delimitada que sirve de soporte a diversos elementos, la presencia de un observador que percibe y la interacción resultante entre dichos factores.

Además, en torno a la percepción Valdés (2017) indica que:

La percepción en el paisaje es el proceso cognitivo y emocional a partir del cual un individuo crea su propia idea del mismo a partir de la apreciación sensible del territorio, por un lado, y de la suma de concepciones culturales y de opiniones personales sobre la realidad de su tiempo. (p. 29)

Para Silva (1993), en dicha percepción del paisaje es posible confrontar el valor de lo bello con lo que es útil y agradable; es decir, será válido percibir e identificar tanto la función estética como la función utilitaria del paisaje.

Esta representación de la correspondencia a un fin, es decir, la coincidencia del objeto con la idea del fin al que se le destina, es lo que Ziehen llama la representación telética. La sensación de goce que lo útil nos produce surge y desaparece con la idea de adecuación a un fin (Silva, 1993, p. 97).

A su vez, nos recuerda que para Kant la característica esencial de lo estético es la ausencia de la representación de fin. En tal sentido, el valor de la belleza puede ser identificado tanto en la naturaleza como en lo creado por el hombre. El paisaje es percibido estéticamente no por su utilidad inmediata, 
sino también por lo que nos sugiere y evoca como símbolo dentro de las ideas humanas (Silva, 1993). De esta manera, ambos juicios son plenamente válidos a ojos del observador humano: un juicio utilitario, que proporciona beneficios cuantitativos, y un juicio estético, que nos permite obtener beneficios cualitativos.

¿Es el paisaje un ente estático? Maderuelo (2010) indica que el paisaje es dinámico y está sometido a cambios constantes dependientes de su percepción y que, llegado el caso, "es preciso intervenir en él, pero siempre con equilibrio, tratando de conseguir que las innovaciones que exige nuestro tiempo se estudien con el máximo rigor" (p. 27) a fin de no alterar sus rasgos esenciales, hecho sistemáticamente ignorado por el hombre. Las implicancias de dichos cambios se refieren "a la variación que sufre su estructura, composición y funcionamiento en un lapso de tiempo determinado. Este está directamente relacionado con el cambio de estado de una o más de sus variables" (Etter, 1991, p. 50).

\section{Paisaje natural y paisaje cultural}

El paisaje, al tratarse de una entidad estudiada desde diversas disciplinas y valorable desde sus múltiples características, puede clasificarse de innumerables maneras atendiendo al enfoque o punto de partida de estos. Una aproximación clásica de base positivista que se remonta al origen mismo del estudio del problema del paisaje a partir de la geografía es la distinción entre paisaje natural y paisaje cultural (Ludeña, 2009, p. 262). La base de dicha distinción es la acción del hombre: por un lado, el paisaje natural es aquella porción de territorio que no ha sido modificada por el accionar del hombre, es decir, es un ecosistema donde los factores bióticos y abióticos permanecen en equilibrio y, por lo mismo, es un paisaje donde el observador podrá emitir un juicio estético de impresión positiva.

Por su parte, el paisaje cultural es entonces todo lo opuesto, es aquel territorio transformado por la actividad humana. A través del tiempo, dicha definición se ha hecho más compleja debido a los procesos ambientales, sociales y culturales que definen al paisaje.

Una definición muy apropiada la encontramos en el Plan Nacional de Paisaje Cultural de España, aprobado en el 2012, que lo define como "el resultado de la interacción en el tiempo de las personas y el medio natural, cuya expresión es un territorio percibido y valorado por sus cualidades culturales, producto de un proceso y soporte de la identidad de una comunidad". El paisaje cultural es, entonces, el resultado de la impronta del componente humano y de los procesos socioculturales sobre la naturaleza. Por muy modesta que sea la interacción hombre-naturaleza, hay paisaje.

Al tratarse de una entidad dinámica que varía conforme a dichas interacciones es necesario, siguiendo el Plan Nacional de Paisaje Cultural de España (2012), "conocer la evolución histórica del paisaje, identificar y caracterizar 
sus principales rasgos y estimar sus valores para poder actuar [...] a favor de la salvaguarda y fortalecimiento de los valores culturales y ambientales que definen su carácter e identidad".

Es a partir de la identificación de estos rasgos y valores que podemos definir el rol predominante de dicho paisaje. Por la vertiente utilitaria del paisaje y los beneficios que proporciona, es reconocible la función que desempeña en el sistema de interacciones humanas. Etter (1991) clasifica dichos sistemas en productivos, extractivos, transformativos, de asentamiento y de conservación. Del lado de la percepción estética del paisaje, al tratarse de un fenómeno subjetivo, las posibilidades son innumerables. Todas estas características hacen del paisaje cultural una realidad compleja, para su adecuada gestión se requiere conocer todos los componentes que le dieron origen y que lo sostienen a lo largo del tiempo.

\section{El paisaje urbano}

El paradigma de la transformación del medio natural por el hombre son las ciudades que conforman el llamado paisaje urbano, comprendido dentro del paisaje cultural. Fue el arquitecto y urbanista Gordon Cullen quien, en el año 1961, dio origen al concepto de paisaje urbano que describió como la capacidad humana de formarse una idea del espacio urbano, en el cual se percibe lo que se nos ofrece delante, activándose recuerdos y emociones a través de los sentidos como la vista, el lugar percibido y el contenido. Por ello, Cullen cree necesario abordar las ciudades de acuerdo a la dinámica de los usuarios y su trabajo nos brinda las herramientas para el diseño mediante la secuenciación espacial y el disfrute estético del paisaje urbano (Lugo, 2019).

Se considera que, evaluados en distancias asequibles a la vista y a la dimensión humana, la interacción entre el usuario y los diversos elementos del paisaje urbano se realiza a través de parámetros como la escala, la proporción, el recorrido, así como los objetos situados en dicho espacio y que ofrecen tanto confort a través de su uso como un valor estético distinto de las experiencias cotidianas, a través de la observación de dicho paisaje (Briceño-Ávila, 2018).

El paisaje urbano es, entonces, la expresión de todo lo que es posible percibir en los espacios de una ciudad. Así, tenemos que el espacio público se erige como el "dominio de lo colectivo", conformado por las calles, las plazas, los parques y los diversos elementos que representan la dimensión humana de la urbe. Existe, simultáneamente, un carácter objetivo y subjetivo, en la forma en que el observador percibe al espacio y le asigna atributos estéticos como paisaje.

Para Gehl (2014) los espacios públicos deben ser de calidad, y a través de ellos se genera interacción, se refuerzan los vínculos entre las personas a fin de crear una identidad común, conformando así ciudades más humanas. Por su parte, Aristizabal y Loaiza (2017) señalan que estos espacios públicos son oportunidades para diseñar ciudades que hagan posible una mejor convivencia entre las personas, el desarrollo cultural de la colectividad y el afianzamiento de los 
valores cívicos de las sociedades abiertas modernas, así como la tolerancia y la participación ciudadana activa tanto de residentes como de visitantes. A fin de garantizar una mayor equidad en la ciudad, se elaboran normas con la finalidad de regular el accionar y el comportamiento individual dentro de la colectividad. Estas normas buscan uniformizar y estandarizar procedimientos de intervención en nuestra ciudad; por ende, también definen el rol y el uso del paisaje urbano, que puede ser variable.

\section{El paisaje como patrimonio}

Mata (2007) afirma que la actividad humana impacta sobre el ecosistema original del territorio de manera que le "imprime carácter al territorio, de esta manera se produce el primer entendimiento del paisaje como patrimonio [...] por todo lo que el paisaje tiene de documento, de libro abierto de historia del territorio" (p. 8). Si el paisaje es el resultado de procesos históricos en un determinado territorio, que a su vez son considerados sucesos significativos para el componente humano de dicho territorio, que conforman una entidad heredada del pasado y con capacidad de ser transmitida a las generaciones futuras, entonces dicho paisaje tiene también valor patrimonial.

Existen diversos dispositivos surgidos a través del consenso científico que definen el valor patrimonial del paisaje. De todos estos, a nivel internacional, el más importante es el de la UNESCO (Organización de las Naciones Unidas para la Educación, la Ciencia y la Cultura) que, en la Convención sobre la Protección del Patrimonio Mundial, celebrada en París en 1972, señala entre las consideraciones de patrimonio cultural a "los lugares: obras del hombre u obras conjuntas del hombre y la naturaleza, así como las zonas, incluidos los lugares arqueológicos que tengan un valor universal excepcional desde el punto de vista histórico, estético, etnológico o antropológico". Aquellos lugares de singular excepcionalidad que cumplen dichas características reciben la distinción de Patrimonio de la Humanidad.

Para el año 2000 ya no se hablaría de lugares, sino de paisajes en dos sendos dispositivos: la Carta de Cracovia y el ya mencionado Convenio Europeo del Paisaje. En la primera se indica expresamente a los paisajes como patrimonio cultural, ya que son "el reflejo de una interacción prolongada a través de diferentes sociedades entre el hombre, la naturaleza y el medioambiente físico. [...] En este contexto, su conservación, preservación y desarrollo se centra en los aspectos humanos y naturales". En la segunda se indica la definición y los aspectos generales de los paisajes, así como la normativa legal mínima para la cooperación internacional entre los países firmantes.

A nivel nacional el organismo encargado de otorgar estas distinciones patrimoniales es el Ministerio de Cultura del Perú. La Ley General del Patrimonio Cultural de la Nación (2004) indica entre los bienes integrantes de dicho patrimonio a "ambientes y conjuntos monumentales, centros históricos, [...] y su entorno paisajístico”. 


\section{La conservación y sostenibilidad del paisaje}

El Plan Nacional de Paisaje Cultural de España (2012) indica que:

El futuro del paisaje depende de las actuaciones que se llevan a cabo en el presente, en cada momento. Para obrar con coherencia y asegurar su sostenibilidad es necesario partir de un conocimiento exhaustivo del paisaje, que implica identificar sus elementos constitutivos, articularlos en el Todo paisajístico y desentrañar los procesos históricos y actividades socioeconómicas que han incidido en su configuración. La finalidad no debe ser fosilizar el paisaje - desafortunadamente en muchas ocasiones se confunde proteger con fosilizar-, sino propiciar una evolución capaz de garantizar la pervivencia de sus valores y de su carácter.

Por su parte, Rivera (2010) afirma:

es importante comprender y respetar el carácter de los paisajes, y aplicar las adecuadas leyes y normas para armonizar la funcionalidad territorial con los valores esenciales. La conservación [...] implica la consideración de valores sociales, culturales y estéticos. (p. 8)

Con la identificación del paisaje como patrimonio por la valoración de sus atributos es deseable evitar alterar sus características esenciales con el objetivo de asegurar la conservación de sus particularidades y valores inmateriales para un óptimo disfrute en el presente y en el futuro, lo que se consigue a través de una cuidadosa gestión mantenida en el tiempo.

Ahora bien, ¿por qué no asegurar la continuidad del paisaje conservado para el futuro manteniendo su esencia y reduciendo el impacto actual de nuestras acciones? Es entonces necesario asegurar su sostenibilidad. Ya en 1987, el informe Brundtland había definido al desarrollo sostenible como "el desarrollo que satisface las necesidades del presente sin comprometer la capacidad de las generaciones futuras para satisfacer las suyas" de manera que el uso de los recursos naturales sea conforme a las posibilidades del planeta. Los paisajes deberán desenvolverse bajo tres premisas: crecimiento económico equitativo, conservación del medioambiente y desarrollo social.

En la actualidad, los objetivos de políticas de sostenibilidad están regidos por la Agenda 2030 sobre el Desarrollo Sostenible, aprobada en el 2015 por la ONU (Organización de las Naciones Unidas). En el caso del bosque El Olivar cobra especial importancia el objetivo 15, que se refiere a los ecosistemas terrestres: "Gestionar sosteniblemente los bosques [...], detener la pérdida de biodiversidad" lo que nos lleva a considerar la importancia de los bosques urbanos para la calidad de vida de la población. En medio de la lucha actual por el espacio público y la primacía de lo verde, los árboles son un componente fundamental en la gestión sostenible de las ciudades por los beneficios generados. Es interesante recordar que donde prevalecen hoy las ciudades, los árboles eran antes los protagonistas. 
Priego (2002) condensa los siguientes beneficios de la vegetación urbana: a) ambientales, en cuanto contribuyan a la mejora de indicadores del ecosistema; b) sociales, que generan un aumento de la calidad de vida de la población; y c) económicos, porque impactan en el valor de suelo del entorno inmediato.

En el caso de estudio que nos ocupa, resultan especialmente importantes los beneficios ambientales del árbol de olivo. Ruiz et al. (2018), en un estudio para el proyecto Olivares Vivos de España, confirma al olivo como un cultivo estratégico para recuperar la biodiversidad del territorio, al ser un excelente refugio de la flora y fauna (como es el caso de las aves que contribuyen a la sanidad de los árboles), en consonancia con buenas prácticas agrícolas que resultan en un apreciable beneficio económico. Pocas especies vegetales presentan tan buena oportunidad de conciliar la naturaleza con la acción del hombre, el interés estético con el aprovechamiento utilitario. El creciente interés por actividades productivas sostenibles renueva la mirada sobre las virtudes del árbol de olivo.

\section{TRANSFORMACIONES DEL PAISAJE DEL BOSQUE EL OLIVAR}

Como parte del análisis de las transformaciones del paisaje del bosque El Olivar, se han identificado cuatro etapas plenamente caracterizadas, desde la época prehispánica hasta la actualidad. Tomamos como indicador principal la cantidad de árboles de olivo en diferentes momentos de la historia del parque, conforme a fuentes documentales verificables, como evidencia del rol predominante del paisaje del actual bosque El Olivar, producto de la percepción y de la actividad humana sobre el territorio de estudio.

\section{Primera etapa: paisaje sostenible}

El paisaje natural del territorio que actualmente ocupa el distrito de San Isidro fue modificado inicialmente por los huallas (tribu preínca que pobló la zona de estudio desde el siglo vi), quienes dejaron evidencia de su asentamiento en el lugar a través de la huaca Huallamarca, palabra quechua que justamente significa comarca de los huallas. La huaca, construida con millones de adobes fabricados in situ, estaba ubicada cerca del camino real incaico, que da nombre a la actual avenida Camino Real, y que se servía de las aguas del río Huatica para irrigar los campos de cultivo que se ubicaban en torno a ella (Municipalidad de San Isidro, 2014).

Sin embargo, esta estrategia de modificación del paisaje natural consistió en la integración y el uso adecuado de los recursos que se podían producir en él, haciendo que el hombre obtenga beneficios a la vez que mantuvo el equilibrio del ecosistema (Dolorier, 2013). Ludeña (2009) indica:

Un rasgo central de las sociedades preínca e inca es que las relaciones entre ellas y naturaleza implican relaciones de adaptación y relación armónica. [...] Puede afirmarse, en cierto sentido, que existía una relación de equilibrio entre sociedad y naturaleza. (p. 269) 
En la actualidad, tanto la huaca Huallamarca como el camino real, el cual formó parte del Gran Camino Inca o Qhapaq Ñan, se han integrado a la trama urbana de la ciudad de Lima. En tal sentido, la primera etapa del paisaje del que sería el bosque El Olivar está claramente caracterizada por el sabio manejo sostenible que nuestros antepasados prehispánicos le dieron al territorio costero, a fin de poder obtener beneficios directos de la tierra al asentarse en ella y cultivarla de manera extensiva, a través de intervenciones limitadas, lo que causó el mínimo impacto y no afectó el equilibrio natural del ecosistema.

\section{Segunda etapa: paisaje productivo}

La conquista española transforma por completo al territorio: el paisaje asume su lado utilitario y se impone una secularización del territorio sagrado de los antiguos peruanos. Ludeña (2008) señala que "para el colonizador el paisaje (y por ende la naturaleza) no representan una extensión animista como en la imaginería religiosa prehispánica, sino una fuente de recursos a explotar y depredar" (p. 70). Así, en 1559, don Antonio de Ribera, futuro alcalde del cabildo limeño, introduce por primera vez el olivo en el Perú al traer los primeros almácigos de esta especie desde España, los cuales fueron sembrados en la hacienda de su propiedad conocida hoy como la Huerta Perdida. Pocos años después, unos retoños fueron trasplantados al sur de Lima, en la hacienda Limatambo, propiedad de los frailes de Santo Domingo, dando origen al actual bosque El Olivar (Municipalidad de San Isidro, 2014).

No se cuenta con datos precisos respecto a la cantidad de olivos plantados inicialmente; sin embargo, de acuerdo a un estudio realizado en el 2017, se ha determinado que San Martín de Porres (1579-1639) sembró unos olivos en la zona ocupada actualmente por el bosque; en tal sentido, este será el dato que se tomará para poder determinar el número inicial de estos. Las referencias bibliográficas consultadas nos indican el siguiente episodio de la vida del santo limeño, según testimonio de su asistente Juan Vásquez Parra:

En el mes de agosto de 1637, Martín y Juancho se trasladaron a la hacienda de Limatambo (hoy El Olivar de San Isidro), donde plantaron 700 esquejes de olivo en menos de 15 días. Sucedió que las ramas retoñaron hojas al tercer día de riego, es por esta acción sobrenatural que fue considerada un milagro durante el proceso de beatificación de Martín de Porres Velázquez. (Vásquez, citado por Vargas, 2017, p. 61)

En otro pasaje de la misma fuente, en un diálogo entre fray Martín y su asistente, dice textualmente el primero:

Es que poda fray Francisco el viejo olivar y cortaremos estacas, para desde el camino real hasta el molino hacer un nuevo olivar, para que estos muchachos tengan en el tiempo de adelante con qué poder pasar, que el olivar que hoy hay es ya viejo y se irá criando otro nuevo y de aquí a treinta años, que ya estos serán hombres maduros, dirán que Dios perdone a quien plantó este olivar. (Vargas, 2017, p. 61) 
De la lectura de este relato podemos inferir que San Martín de Porres replantó aproximadamente setecientos olivos en la zona ocupada por el actual bosque. En el 2017, al realizar los estudios de datación mediante el método Santander, se logró identificar a un olivo sobreviviente de los plantados por el santo limeño, arrojando una edad de 374 años. Al paso de los años, el olivar fue en aumento y para 1730 alcanza la apreciable cantidad de dos mil árboles (Mascco, 2018, p. 65).

Figura 1.

Olivo plantado por San Martín de Porres

Fuente: "El Olivar: ubican árbol de olivo plantado por San Martín de Porres" (2017)

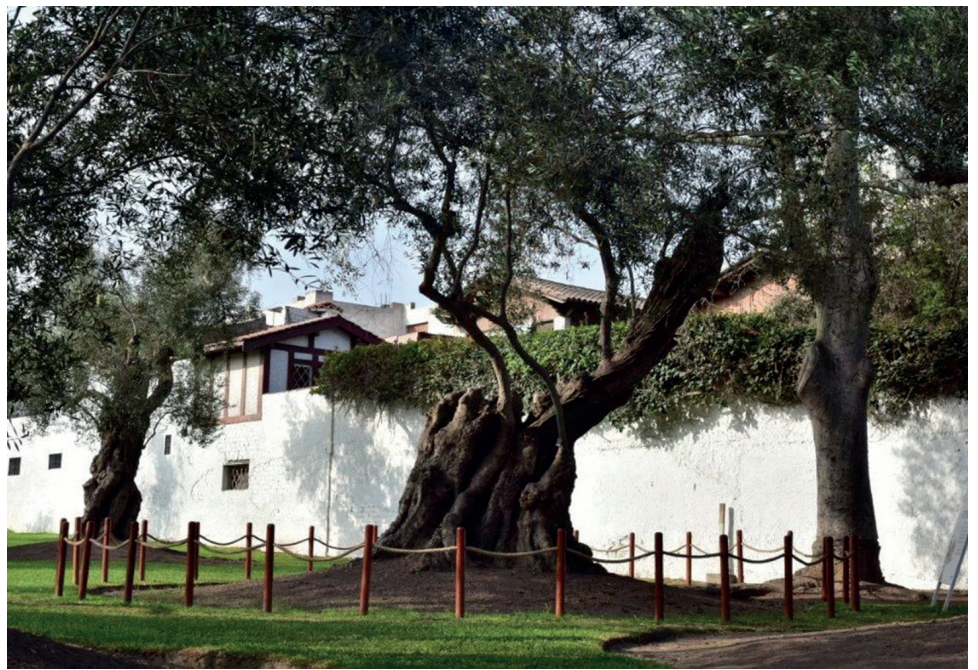

En 1777, el fundo fue adquirido por Rosa María Gutiérrez de Cossío, III condesa de San Isidro y esposa de Isidro de Abarca y Gutiérrez de Cossío. Desde ese año se conoció a la zona como Hacienda de San Isidro por el título condal de sus propietarios, quienes cercaron nuevamente la hacienda tras el colapso de los muros originales con el terremoto de 1746 y consolidaron la explotación intensiva de los olivos, como se puede apreciar por el torno y el molino aún existentes, introducidos por esos años para la mejora de la producción de aceite (Orrego, 2008).

La guerra de independencia peruana causa estragos en el bosque de olivos, sin embargo, el V conde de San Isidro, Isidro Cortázar y Abarca, logra impedir que los realistas talen por completo el olivar de su propiedad, que en el año 1828 había incrementado el número de olivos hasta llegar a los 2338 árboles (Mascco, 2018, p. 65). Con el inicio de la república, tras un período de abandono, la hacienda es adquirida por José Gregorio Paz Soldán en 1853, pasando en lo sucesivo a poder de sus descendientes (Municipalidad de San Isidro, 2014). Según Dargent (2018), cuatro años antes, en el inventario practicado en 1849 se habían contado 1936 olivos, 990 olivos viejos y 946 nuevos.

Que el viejo olivar seguía en plena explotación económica en la segunda mitad del siglo xIx lo demuestra el hecho de la participación del "Aceite de Oliva de 
San Isidro" en la Exposición Industrial de Lima realizada en 1869, presentado por la familia Paz Soldán como uno de los principales comestibles producido en las inmediaciones de Lima (Dargent, 2018, p. 68).

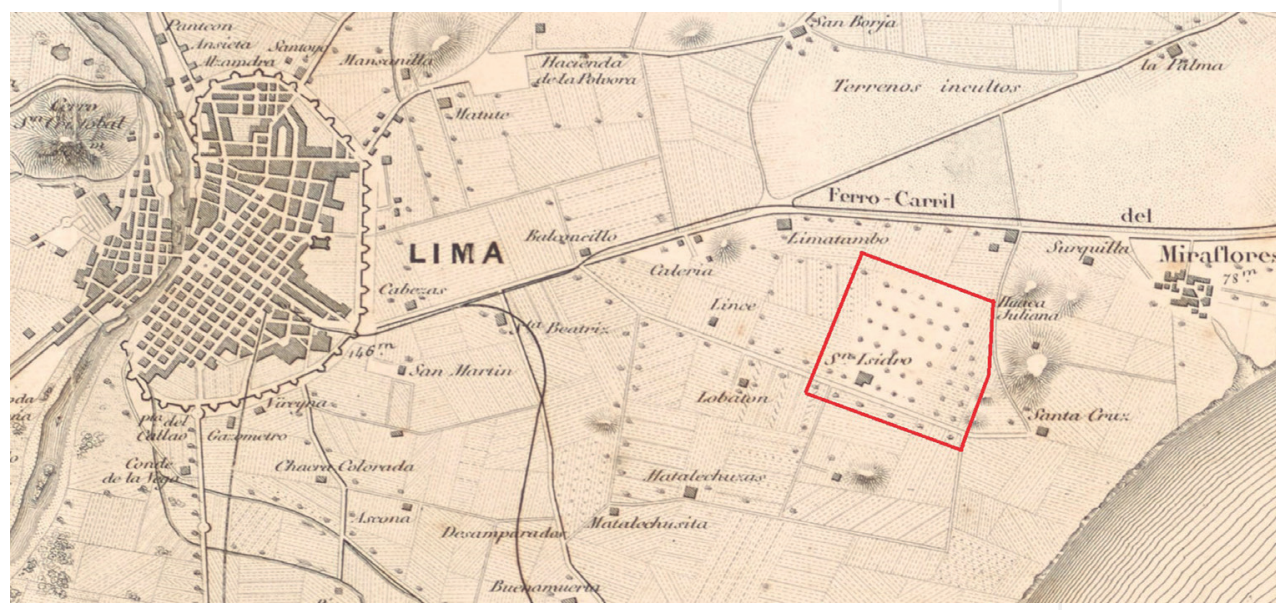

En esta etapa la transformación del paisaje es motivada por la visión utilitaria que los nuevos habitantes del valle del Rímac le dieron al territorio costero, siendo el hecho más significativo la introducción de una especie foránea como es el olivo que afortunadamente logró adaptarse en nuevas tierras. La acción humana es más preponderante, a través de la explotación de las parcelas que conformaron la hacienda San Isidro, a fin de poder obtener el aceite a partir de las aceitunas cultivadas tradicionalmente primero y luego mediante el uso de tecnología industrial; sin embargo, el territorio pudo mantener un cierto equilibrio en un entorno suburbano, al hallarse próximo a diversos asentamientos.

\section{Tercera etapa: paisaje recreativo}

El bosque de olivos y su entorno se mantuvieron a salvo de la incipiente expansión urbana de Lima hasta principios del siglo xx, cuando ocurrió una nueva transformación. Durante el segundo gobierno del presidente Augusto B. Leguía, es decir, el Oncenio (1919-1930), se conmemoraron dos fechas sumamente importantes para nuestro país: el centenario de la independencia del Perú en 1921 y el centenario de la batalla de Ayacucho en 1924. En tal sentido, fue durante este gobierno que Lima inició una nueva fase de expansión a partir del fomento de las obras públicas mediante el endeudamiento con capital extranjero, proveniente de los Estados Unidos, que sustituyó la influencia económica del capital inglés (Martucelli, 2006).

El plan leguiísta de desarrollo nacional se denominó Patria Nueva y uno de sus objetivos más ambiciosos era la modernización y el embellecimiento de Lima, para lo cual se ejecutaron diversos proyectos a fin de dejarla a la altura de tales conmemoraciones; como, por ejemplo, la gran avenida Leguía, cuya 
Figura 3. Avenida

Leguía (actual avenida Arequipa)

en 1930

Fuente: Arheidt y Wieser (1997,

p. 76) configuración original se aprecia en la figura 3, que fue inaugurada en 1921 y que permitía conectar el centro de Lima con los nuevos barrios residenciales ubicados al sur de la ciudad. Con la caída del régimen tomó su nombre actual: avenida Arequipa.

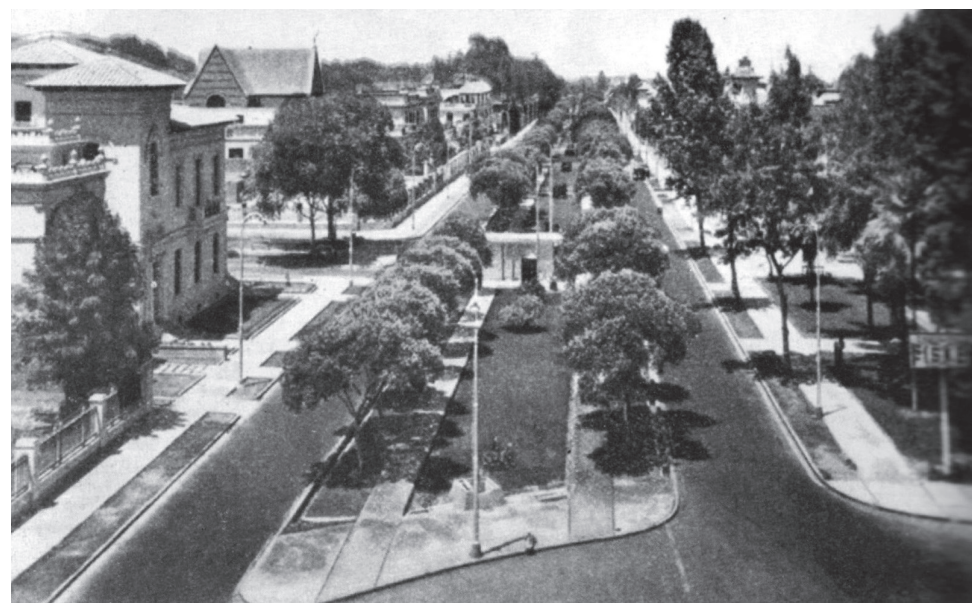

Viendo las posibilidades que la apertura de dicha vía generaba en los suburbios de Lima, en 1920 la Compañía Urbanizadora San Isidro implementó un nuevo concepto residencial cuyo diseño estuvo a cargo del arquitecto, urbanista y escultor Manuel Piqueras Cotolí, el cual consistía en una urbanización que tomó como punto de partida el trazado original de los canales ubicados en la antigua hacienda San Isidro constituyéndose en un ejemplo único, pintoresco y muy valioso de trama urbana en la ciudad de Lima (Coronado, 2018 , p. 186). Dentro del parque se separaron para la venta 41 manzanas de diversos tamaños, con un área aproximada de $22400 \mathrm{~m}^{2}$ (Municipalidad de San Isidro, 2014).

En la figura 4 se aprecia el diseño original de la urbanización, el cual contemplaba el futuro trazado de la avenida Leguía e incorporaba en su diseño la parcela que fuera destinada para la siembra de olivos en la hacienda San Isidro. Dargent (2018) cuenta que, durante la concepción de la nueva urbanización, los propietarios Francisco Moreyra y Luisa Paz Soldán manifestaron su deseo de mantener la extensión del olivar "celosamente respetada” y que las aceitunas sean de libre disposición para el público. Para el año 1924, el trazado de la avenida Javier Prado dividió la urbanización en dos partes alterando para siempre su configuración inicial. Dicha situación se mantiene hasta a la actualidad (Orrego, 2013). 


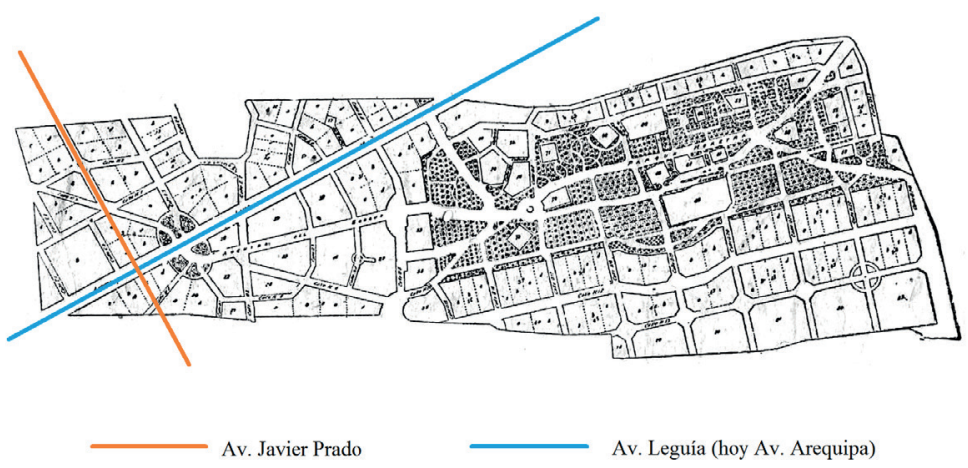

La figura de Piqueras es determinante en la transformación del paisaje del bosque El Olivar en una propuesta urbana radicalmente distinta al modelo imperante. Formado en su país natal España, donde se vio influenciado por las beax arts francesas, fue un estudiante destacado y un escultor eximio que vino al Perú como profesor de escultura de la Escuela Nacional de Bellas Artes, convirtiéndose en un personaje destacado en la arquitectura, el urbanismo y la escultura peruana. El mayor aporte de Piqueras Cotolí, sin duda, fue el de haber abordado la creación de un estilo neoperuano con una visión de síntesis racial. Piqueras Cotolí afirmaba que

estudiando la Raza Nueva, aún en formación, se perciben la influencia española e india y, al cruzarse, los estilos español y aborigen deben combinarse como los seres vivos de los cuales biológicamente considerados puede llegar a formarse una sub-raza. (Piqueras, citado por López, 2011, p. 205)

La fusión de ambos estilos se debe manifestar visualmente en la arquitectura, el urbanismo y las artes, con lo que se crea un nuevo estilo autóctono que consolida así su visión y su manera de pensar en torno a su producción personal. Piqueras realiza una mirada hacia el interior para poder realizar un modernismo acorde con las raíces del lugar y que busca reforzar la identidad de lo edificado sobre el paisaje natural (López, 2011).

En consecuencia, como señala Martuccelli (2006), "en la zona de El Olivar de San Isidro se ensayó un urbanismo de trazo libre, con lotes dispersos en medio de áreas verdes: una manera novedosa de plantear una urbanización, llena de luz, aire y distinción" (p. 259). Asimismo, Ludeña (2009) señala que, a diferencia del típico trazado a modo de damero con base en ejes y lotes ortogonales, usado desde la fundación española de la ciudad, la nueva concepción urbana planteada por Piqueras Cotolí creaba espacios abiertos comunicados entre sí en cuyo interior se ordenaban las viviendas en contacto directo con la naturaleza. El municipio mantuvo dicha disposición comprando algunos lotes destinados para edificación a fin de incorporarlos al espacio del bosque.
Figura 4. Plano del trazado original de la urbanización diseñada por Piqueras Cotolí

Fuente: Municipalidad de San Isidro 
Sobre estas virtudes eran especialmente conscientes los promotores del nuevo proyecto urbanístico cuando difundieron la publicidad que se aprecia en la figura 5, donde se muestra al

Olivar de San Isidro, que se convertirá en un parque público [...] Si Ud. soñó alguna vez vivir en una alegre casa de campo rodeada de espléndidos jardines sombreados por muchos árboles centenarios y frondosos, apresúrese a escoger un terreno. (Mundial, 1922, p. 37)

Figura 5. Publicidad de la Compañía Urbanizadora San Isidro Ltda. para hacerse de un terreno en el nuevo Olivar de San Isidro

Fuente: Mundial $(1922$, p. 37)
Esta lotografia muestra un aspecto del hermoso Olivar de San Isidro, que se convertirí en un parque público 30 veces más grande que la Plaza de Armas de Lima.

El Otivar de San Isidro se halla a la acera derecha de la Avenida Leguia que une Lima y Miraflores, (ya asfaltada de un lado $y$ totalmente alumbrada).

Si Ud. soñó alguna vez vivir en una alegre casa de campo rodeada de espléndidos jardines sombreados por muchos árboles centenarios y frondosos, apresúrese a escojer un terreno en el Olivar.

agua, desague, veredas-Grandes facilidades de pago

\section{Compañía Urbanizadora San Isidro Ltda.}


Al revisar la figura 6, la fotografía aérea de 1943, se puede apreciar claramente que la intención de Piqueras no era continuar el trazado de damero extendido en el crecimiento de la ciudad, sino más bien se evidencia su visión personal al crear una nueva urbanización condicionada por las preexistencias, las que respeta e integra al nuevo trazado, generando así una nueva trama urbana. El creciente poblamiento de esta y otras urbanizaciones, así como la conexión con Lima y Miraflores, a través de la avenida Leguía (ahora avenida Arequipa), determinaron la creación del actual distrito de San Isidro en 1931 (Municipalidad de San Isidro, 2018).
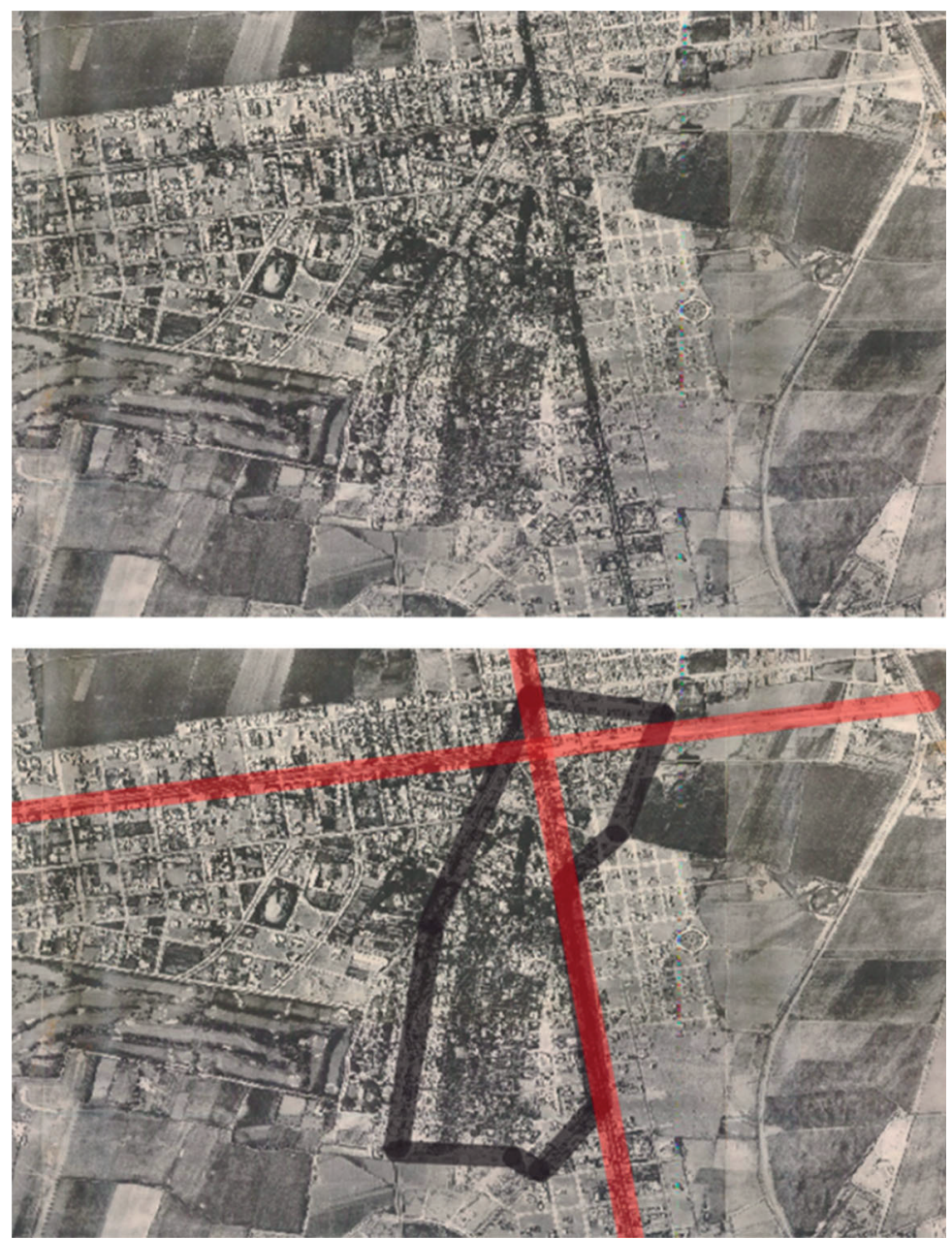

Figura 6. Fotografía aérea de 1943, superponiendo la Trama de la Urbanización San Isidro junto a los principales ejes de desarrollo de esos años, la avenida Arequipa y la avenida Javier Prado

Elaboración propia, basada en imagen recuperada de Municipalidad de San Isidro (2014a) 
Figura 7. Captura de pantalla del video San Isidro, ciudad jardín

Fuente: Biblioteca Nacional del Perú

(1940)
El afianzamiento del viejo bosque de olivos como nueva área de esparcimiento determina la aparición de las primeras alteraciones de su naturaleza. Como se observa en la figura 7, hacia 1945 se construye una laguna que se configura como el punto de encuentro del bosque, rodeada de nuevo mobiliario urbano (Villamón, 2016, p. 73). Posteriormente, se instalan una cancha de básquet y una pista de patinaje para uso de los vecinos y también de visitantes de los distritos cercanos. El bosque El Olivar encuentra una nueva utilidad dentro del paisaje urbano por parte de los residentes de la nueva urbanización, quienes demandaban espacios para el ocio y recreación, lo que pone a la vez en peligro a su naturaleza.

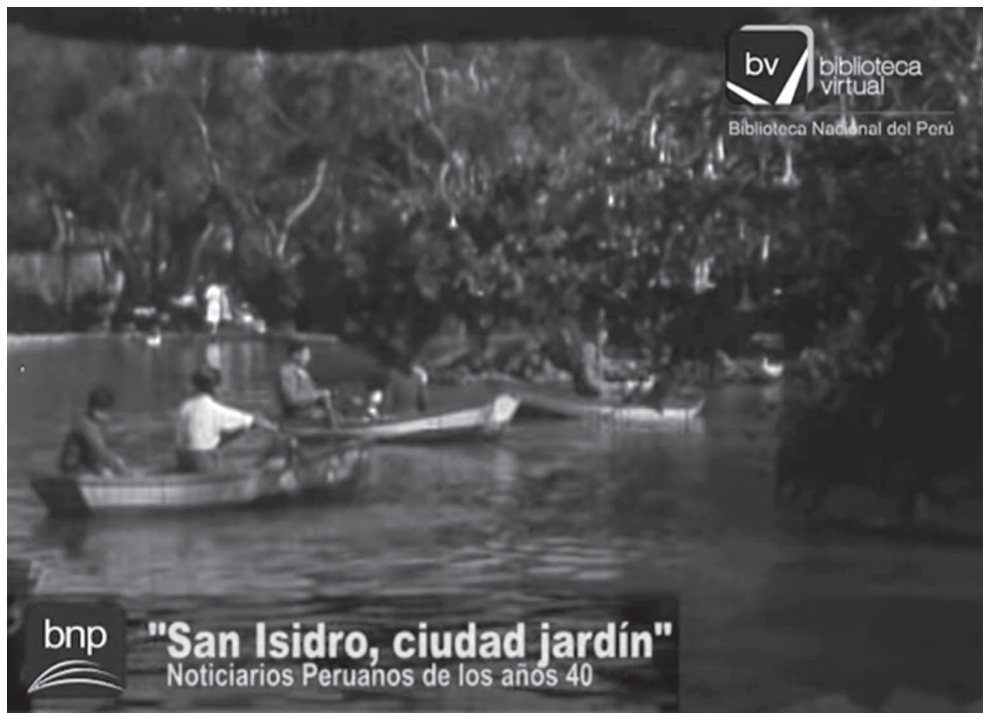

En la figura 8, otra captura del mismo video, se muestra el nuevo camino y el sistema de alumbrado público implementado para poder recorrer el bosque de olivos. Asimismo, se aprecia el estilo arquitectónico original de las viviendas del Bosque, el estilo tudor. El bosque asume cada vez más las características de un parque urbano común, sin tomar en cuenta sus características esenciales. 
Figura 8. Captura de pantalla del video San Isidro, ciudad jardín

Fuente: Biblioteca Nacional del Perú (1940)

En ese sentido, el bosque El Olivar sufrió una nueva transformación dado que, al estar rodeado de viviendas y de la gente que las habitaba, se convirtió en parte del nuevo paisaje urbano, donde la principal función de los olivos cesó de ser productiva, para más bien pasar a tener una función recreativa y escenográfica al servicio de los residentes de la nueva urbanización, asumiendo las características de un típico parque urbano, con mobiliario y servicios que no corresponden a las peculiaridades de un auténtico olivar. Esto llevó a un declive de la cantidad de los árboles de olivo como veremos más adelante y a la progresiva pérdida de valor. Afortunadamente, a finales de esta etapa empieza a surgir una conciencia sobre los valores históricos y estéticos del bosque El Olivar, gracias al celo de algunos vecinos y a una mejor comprensión del sitio por parte de las autoridades.

\section{Cuarta etapa: paisaje conservado}

Para 1959, la expansión urbana de Lima ya había envuelto totalmente al bosque El Olivar. En ese año, su importancia como parte del patrimonio de la ciudad fue confirmada al ser declarado Monumento Nacional mediante la Resolución Suprema 577-ED-59 de fecha 16 de diciembre, gracias a la gestión de las autoridades municipales y de vecinos notables como Luis Paz Soldán y Moreyra. El bosque El Olivar se convierte así en un paisaje de importancia patrimonial, comprendiendo un área de 10,7 hectáreas, al servicio de la población local, pero con importancia nacional debido a sus características naturales, como bosque, y artificiales, como urbanización, con gran significado para la colectividad (Municipalidad de San Isidro, 2018).

Dicha declaratoria marca un hito en la historia de El Olivar, pues a partir de ese momento se suceden una serie de dispositivos legales e instrumentos de 
Tabla 1

Normativa nacional, provincial y local referida a la conservación del bosque El Olivar

Elaboración propia gestión, resumidos en la tabla 1 , que muestran el creciente interés por parte de los diversos actores sociales hacia una adecuada conservación de las características propias del bosque, así como poder recuperarlo de las distorsiones generadas por la descontrolada actividad humana de la anterior etapa.

\begin{tabular}{|c|c|c|}
\hline AÑO & NORMA & CONTENIDO \\
\hline 1959 & $\begin{array}{l}\text { Resolución Suprema } \\
\text { n. }{ }^{\circ} 577-E D-59\end{array}$ & Declaración como Monumento Nacional \\
\hline 1989 & $\begin{array}{l}\text { Acuerdo de Concejo } \\
\text { n. }{ }^{\circ} \text { 035-89-MSI }\end{array}$ & $\begin{array}{l}\text { Reglamento de Conservación, Revalorización, } \\
\text { Zonificación y Edificación para la Zona Monu- } \\
\text { mental del Bosque de Olivos }\end{array}$ \\
\hline 1998 & $\begin{array}{l}\text { Resolución Directoral } \\
\text { n. }{ }^{\circ} 410 / \text { INC }\end{array}$ & Declaración como zona monumental \\
\hline 2005 & $\begin{array}{l}\text { Ordenanza } \\
\text { n. }{ }^{0} 127-\mathrm{MSI}\end{array}$ & $\begin{array}{l}\text { Reglamenta el área de influencia de la zona } \\
\text { monumental }\end{array}$ \\
\hline 2006 & $\begin{array}{l}\text { Ordenanza } \\
\text { n. }{ }^{\circ} 950-M M L\end{array}$ & Actualización de la zonificación de San Isidro \\
\hline 2007 & $\begin{array}{l}\text { Resolución Directoral } \\
\text { n. }{ }^{\circ} 404 / \text { INC }\end{array}$ & $\begin{array}{l}\text { Actualización del Reglamento de la Zona } \\
\text { Monumental Olivar de San Isidro }\end{array}$ \\
\hline 2008 & $\begin{array}{l}\text { Ordenanza } \\
\text { n. }{ }^{\circ} 1126-\mathrm{MML}\end{array}$ & $\begin{array}{l}\text { Actualización de la Reglamentación Especial } \\
\text { de la Zona Monumental del Bosque de Olivos }\end{array}$ \\
\hline 2010 & $\begin{array}{l}\text { Ordenanza } \\
\text { n. }{ }^{\circ} 1465-M M L\end{array}$ & $\begin{array}{l}\text { Actualización de la Reglamentación Especial } \\
\text { de la Zona Monumental del Bosque de Olivos }\end{array}$ \\
\hline 2011 & $\begin{array}{l}\text { Ordenanza } \\
\text { n. }{ }^{\circ} 1569-M M L\end{array}$ & $\begin{array}{l}\text { Actualización de la Reglamentación Especial } \\
\text { de la Zona Monumental del Bosque de Olivos }\end{array}$ \\
\hline 2017 & $\begin{array}{l}\text { Ordenanza } \\
\text { n. }{ }^{\circ} 449-\mathrm{MSI}\end{array}$ & $\begin{array}{l}\text { Declara de interés distrital el reconocimiento } \\
\text { como área de conservación ambiental (ACA) }\end{array}$ \\
\hline 2017 & $\begin{array}{l}\text { Decreto de Alcaldía } \\
\text { n. }{ }^{0} 004-2017-A L C / M S I\end{array}$ & $\begin{array}{l}\text { Crea el Consejo Técnico Consultivo del } \\
\text { Bosque El Olivar }\end{array}$ \\
\hline
\end{tabular}

Paradójicamente, a pesar de su importancia, de la Resolución Suprema de 1959 no se conserva mucha información que indique el criterio de catalogación. La indicación que "es deber del Estado velar por la conservación del patrimonio histórico y artístico del país" nos da una idea de que el principal criterio fue la antigüedad del espacio y de los olivos, por sobre su valor de ecosistema, quizás motivada por las intervenciones recreativas que se venían dando en el bosque.

Sin embargo, pasarían muchos años antes de que dicha declaración monumental se viera reflejada en un instrumento legal que defina sus alcances y permita regular plenamente la pertinencia de intervenciones en El Olivar. En 1989 ve la luz el Reglamento de Conservación, Revalorización, Zonificación 
y Edificación para la Zona Monumental del Bosque de Olivos que delimita y sectoriza la zona monumental, que se aprecia en la figura 9, y define los diversos parámetros con los cuales se regulan las futuras intervenciones, a fin de conservar el bosque en su integridad (García et al., 1989). Aun así, tendría que pasar una década más para que el INC (Instituto Nacional de Cultura) aprobara definitivamente la declaración de zona monumental a través de la Resolución Directoral n. ${ }^{\circ} 410$ de 1998, gracias nuevamente a la presión de grupos de vecinos que advirtieron la aparición de edificaciones que ponían en riesgo la integridad del bosque, habida cuenta de que se trataba ya de un monumento nacional. La declaración de monumentalidad se debe, como reza la introducción del Reglamento de 1989, a sus "características históricas, urbanísticas, arquitectónicas y ambientales de singular valor". Es destacable que aquí se introduce la variable ambiental por primera vez.

A partir de entonces, los siguientes dispositivos legales consistieron en adaptar la nueva zona monumental en la zonificación distrital vigente (caso de las Ordenanzas 127-MSI y 950-MML) y en sucesivas actualizaciones del Reglamento de 1989 a nivel nacional, distrital y local, adaptando dichas normas a las recientes disposiciones de mayor jerarquía, así como el creciente interés en la preservación del bosque, lo que permite puntualizar limitaciones de las normas precedentes y rectificar continuamente aspectos edificativos como la altura máxima, los usos permitidos, los retiros, etcétera. De estas, las actualizaciones más importantes son la Ordenanza n. ${ }^{\circ}$ 1126-MML del 2008 y la Ordenanza n. ${ }^{\circ}$ 1569-MML del 2011.

Es durante la gestión de Manuel Velarde (2015-2018) que se renuevan los esfuerzos por actualizar la categorización del bosque, esta vez bajo el enfoque de sostenibilidad. El municipio apunta sus objetivos a obtener la designación del bosque El Olivar como área de conservación ambiental (ACA) por parte del Ministerio de Ambiente debido al

gran valor ecológico, cultural y paisajístico que requiere de un tratamiento especial con fines de conservación local, bajo una dirección estratégica y especializada que armonice la gestión sostenible del ecosistema y su interrelación con el entorno urbano a largo plazo. (Ordenanza n. $\left.{ }^{\circ} 449-\mathrm{MSI}\right)$

Dicha ordenanza declara de interés distrital la obtención de tal reconocimiento.

A lo largo de estas últimas décadas, diversos estudios han contribuido a mejorar el conocimiento en torno al bosque y a sus olivos. Luego de la declaración de Monumento Nacional, en 1967 el ingeniero Luis Deustua realiza un primer estudio encargado por la Municipalidad de San Isidro para establecer las condiciones de mejora del bosque, encontrándose un total de 1102 olivos y 250 árboles de otras especies. Dos años después, un estudio catastral del bosque El Olivar de San Isidro, elaborado por el arquitecto Ramírez Gastón, detectó $2300 \mathrm{~m}^{2}$ invadidos por propietarios en el bosque, que fueron recuperados progresivamente por la Municipalidad. Posteriormente, otro conteo realizado entre 1986 y 1989 halló 1329 olivos y 377 árboles de otras especies. 
Figura 9

Delimitación de la zona monumental del bosque de olivos

Fuente: anexo $1 \mathrm{de}$ la Ordenanza n. 1126-MML

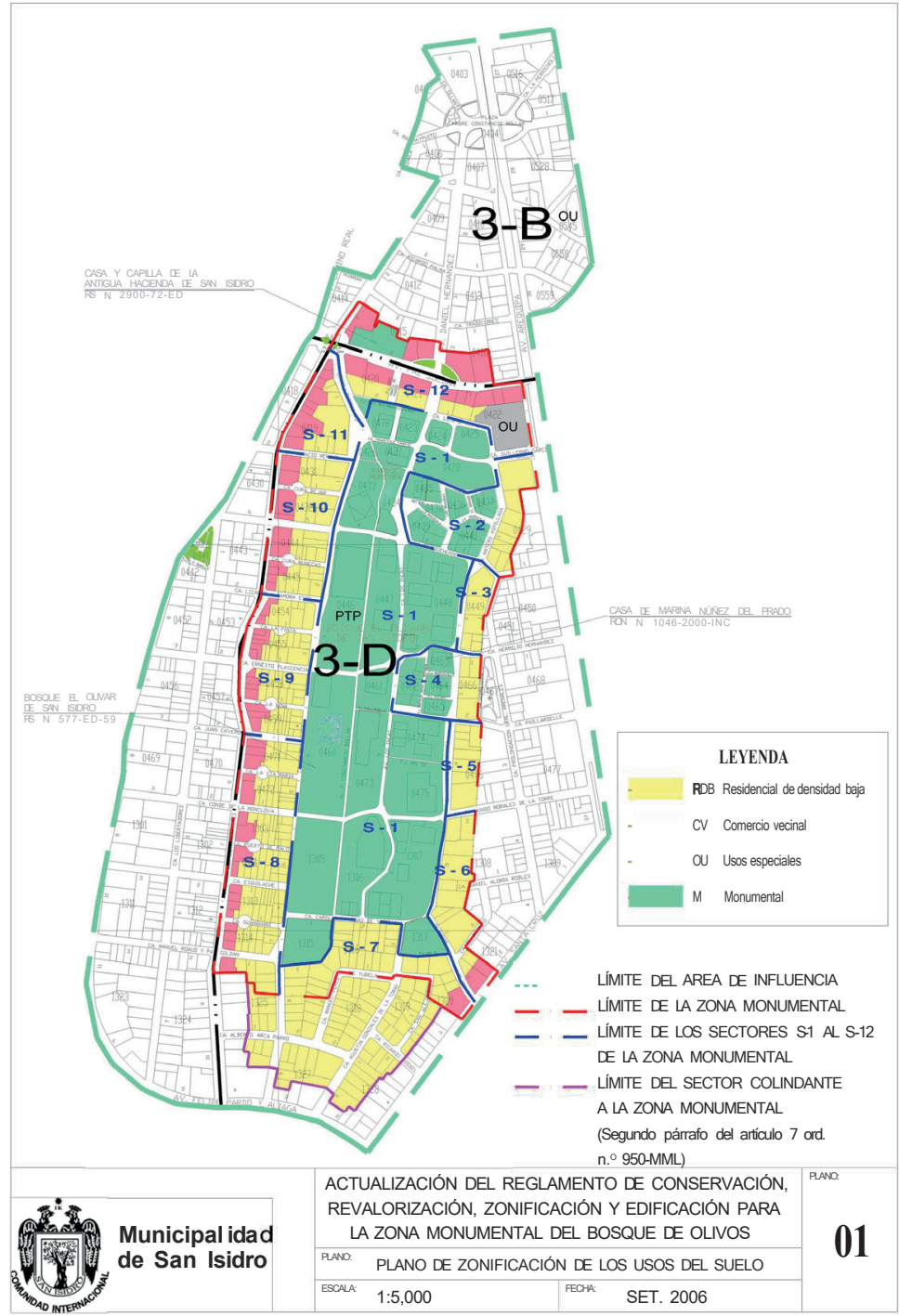

Para el año 1994 un informe indicaba la presencia de 1483 olivos en el bosque, además de contar en el vivero con 200 plantas y 1000 estacas de olivo en semilleros, listos para ser sembradas (Mascco, 2018, p. 66). En el 2017 el inventario municipal indica que existen unos 1674 olivos de diverso tamaño, llegando a tener edades entre 5 y 400 años. Los árboles de olivo han venido sufriendo un deterioro severo que se observa en la ausencia de ramas y copa, ennegrecimiento, caída de hojas, y aparición de plagas; lo que debilita a los árboles y desluce su aspecto (Municipalidad de San Isidro, 2018). 
Conforme a la Memoria institucional de la Municipalidad de San Isidro (2014a), a lo largo de estos años el bosque El Olivar se fue consolidando como uno de los espacios públicos más entrañables y representativos de la ciudad de Lima, con gran afluencia de vecinos y visitantes de otros distritos que buscan áreas de esparcimiento, tanto por sus tradicionales olivos emplazados en uno de los pocos bosques urbanos situados dentro de la capital; por la oferta cultural proporcionada por los diversos equipamientos implementados por diversas gestiones municipales como el Centro Cultural o la Casa Museo Marina Núñez del Prado; y por la realización de actividades únicas en Lima como la observación de aves o ser escenario para fotografías matrimoniales.

La creciente vocación por conservar a El Olivar como referente de la historia del distrito y recuperar el protagonismo que alguna vez tuvieron los olivos se ve reflejada en la convocatoria a los vecinos en el 2018 por parte del municipio para cosechar las aceitunas (ver figura 10), con la finalidad de involucrar a la población en una actividad vivencial que recupera el aspecto productivo de estos árboles.

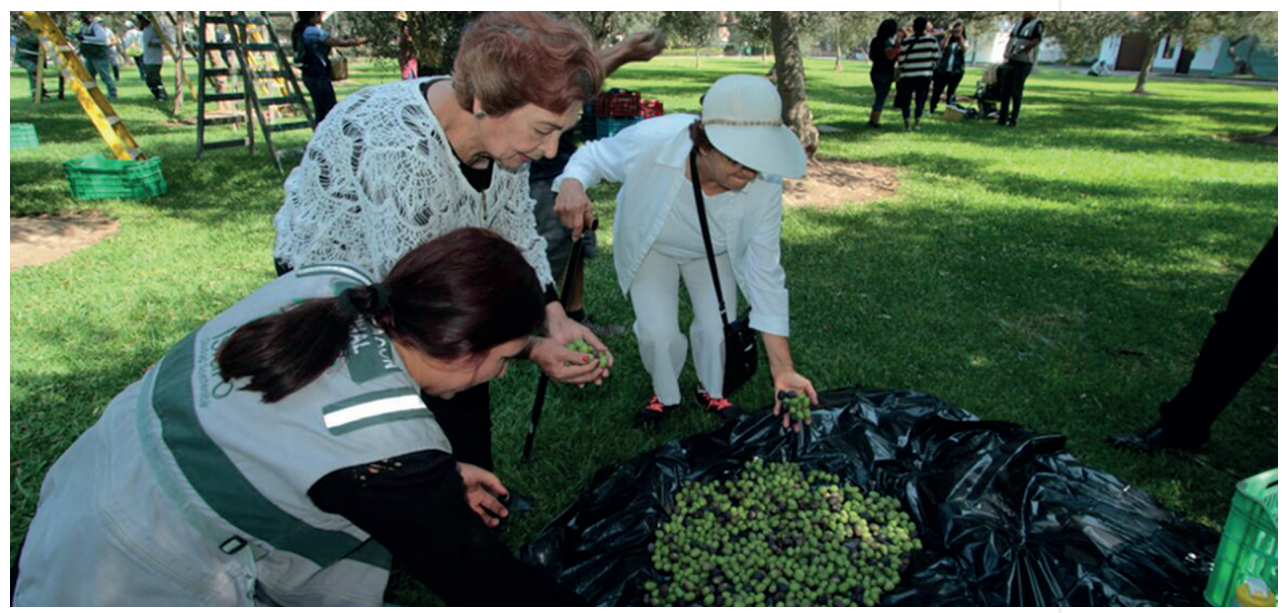

Un aspecto vital para la sostenibilidad y mantenimiento del bosque de olivos es el riego. Dentro de las especies arbóreas encontradas en Lima, el árbol de olivo tiene la característica de requerir poco volumen de riego; según Ascencios y Peña (2014), "una demanda hídrica de 657,47 mm/año, menor que la del césped que es de 1 095,79 mm/año" (p. 209), así como una baja frecuencia de riego; lo que hace incompatible su convivencia con otras especies ornamentales de uso corriente en el paisaje limeño que requieren un mayor volumen de agua. $\mathrm{Y}$ es que dichas especies ornamentales empezaron a proliferar en el olivar desde el momento en que dicho espacio asumió un rol como lugar recreativo y de esparcimiento para los vecinos.

La cuestión del riego es una de las características fundamentales de este paisaje y ha condicionado su devenir a lo largo del siglo pasado; desde que
Figura 10. Cosecha de aceitunas de árboles del bosque El Olivar

Fuente:

Municipalidad de San Isidro (2018) 
abandonó su rol productivo la saturación de dicho riego ha generado un desarrollo desigual y pérdida de olivos en comparación a las demás especies, lo que desvirtuó al olivar en conjunto y puso en riesgo la continuidad de un patrimonio monumental de nuestra nación.

Durante décadas El Olivar ha sido irrigado mediante el sistema de riego por inundación, muy deficiente e insalubre, con las aguas de baja calidad provenientes del río Surco. Dicha inundación, además de generar pudrición de las raíces de los olivos, propicia la aparición de insectos y enfermedades fitosanitarias (Ascencios y Peña, 2014, p. 203).

El Plan Integral del Bosque El Olivar, a cargo de Vera \& Moreno Consultores (2006), propuso controlar la sobreoferta de agua a través de un sistema de riego tecnificado por sistema de aspersión que distinga la diferente cantidad de riego para cada especie; usando aspersores tipo pop-up que estarán espaciados entre sí de manera que permitan regar el césped sin mojar las raíces de los olivos. Estos aspersores serán controlados por electroválvulas. La modernización de la red implica también establecer un método para purificar el agua de riego, ya que suele estar en contacto con los usuarios del bosque, así como un sistema de almacenamiento del recurso hídrico. El ahorro y la mejora de calidad del agua son importantes para la sostenibilidad de este entorno.

En el 2013, finalmente, las autoridades municipales implementaron dicho sistema de riego por aspersión que ahorra el agua, considera la diferenciación de riego entre las especies y evita inundaciones (Silva, 2013). El proyecto fue finalizado en el 2017 y se espera evaluar sus resultados a mediano plazo.

\section{RESULTADOS Y DISCUSIÓN}

Del análisis se ha podido identificar cuatro períodos de transformación del paisaje del bosque El Olivar a lo largo de su historia, conforme a la percepción y al rol predominante de dicho paisaje, tal como se muestra en la tabla 2:

\begin{tabular}{clc}
\hline PERÍODO & \multicolumn{1}{c}{ HITO DE ORIGEN } & $\begin{array}{c}\text { ROL } \\
\text { DETERMINANTE }\end{array}$ \\
\hline $500-1560$ & Asentamiento de los huallas, primeros pobladores & SOSTENIBLE \\
$1560-1920$ & Inicio de producción en la hacienda Limatambo & PRODUCTIVO \\
$1920-1959$ & Trazado de la urbanización San Isidro & RECREATIVO \\
$1959-$ presente & Declaración como Monumento Nacional & CONSERVADO \\
\hline
\end{tabular}

Al mismo tiempo, a través de las fuentes bibliográficas consultadas, podemos establecer la cantidad de árboles de olivo que han existido en años determinados en los cuales se han realizado inventarios, dicha información es señalada en la tabla 3 : 


\begin{tabular}{cccc}
\hline AÑO & $\begin{array}{c}\text { CANTIDAD } \\
\text { DE OLIVOS }\end{array}$ & REFERENCIA & OBSERVACIONES \\
\hline 1637 & 700 & Vargas, 2017 & \\
1730 & 2000 & Mascco, 2018 & \\
1828 & 2338 & Dargent, 2018 & $\begin{array}{c}\text { Máxima cantidad } \\
\text { registrada de olivos }\end{array}$ \\
1849 & 1936 & Dargent, 2018 & \\
1967 & 1102 & Mascco, 2018 & Mínima cantidad \\
& & & \\
1986 & 1329 & Mascco, 2018 & \\
1994 & 1483 & Mascco, 2018 & \\
2017 & 1674 & MSI, 2017 & \\
\hline
\end{tabular}

Tabla 3

Cantidad de olivos registrada durante la transformación del bosque El Olivar

Elaboración propia

Para el análisis gráfico de los datos de la tabla, partimos del hecho de que durante el período de asentamiento prehispánico (a partir del siglo vi de nuestra era) en el valle de Lima los olivos eran inexistentes en la región al tratarse de una especie foránea que fue introducida de España por los nuevos colonizadores. Asimismo, se había supuesto que al inicio del segundo período la cantidad de árboles de olivo aún se mantenía en cero, hasta que se pudo constatar la cantidad de los olivos plantados por San Martín de Porres en 1637, ya que no se cuenta con ningún registro verificable anterior.

En general, luego de registrar los datos correspondientes al número de olivos en todos sus períodos identificados, se ha realizado el promedio ponderado entre los datos extremos a fin de poder evaluar la tendencia de las variaciones sucedidas en el tiempo y para poder dar continuidad visual a la gráfica que se muestra en la siguiente imagen:

Figura 11

Variación de la cantidad de olivos en el tiempo

Elaboración propia

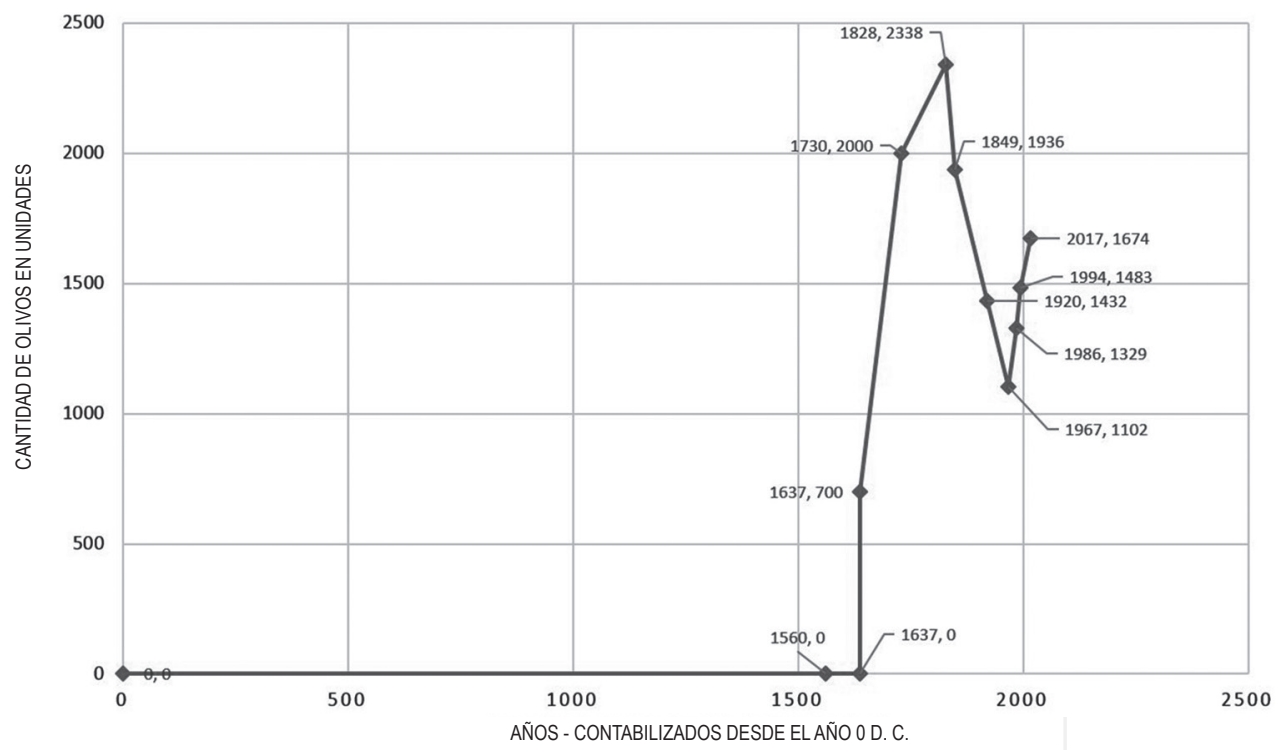


De la figura 11, podemos afirmar lo siguiente:

- $\quad$ La cantidad de olivos aumentó hasta alcanzar su máxima cantidad histórica de 2338 árboles de olivo durante el período de paisaje productivo, es decir, aquella que está relacionada con el aprovechamiento de los olivos para la producción de aceitunas y aceite de oliva.

- La cantidad de olivos disminuye hasta alcanzar su cantidad mínima histórica, de 1102 árboles de olivo al inicio de la etapa de paisaje conservado; es decir, luego de haber pasado por el proceso de urbanización y consolidación urbana que se inició durante el Oncenio de Leguía, tal y como se aprecia en la figura 12.

- $\quad$ Entre el período de 1828 a 1967, es decir, en 139 años, se perdieron aproximadamente unos 1236 árboles de olivo coincidentemente durante la etapa de transformación, consolidación y auge del paisaje urbano, en la cual cambió el uso y el rol preponderante del bosque de olivos.

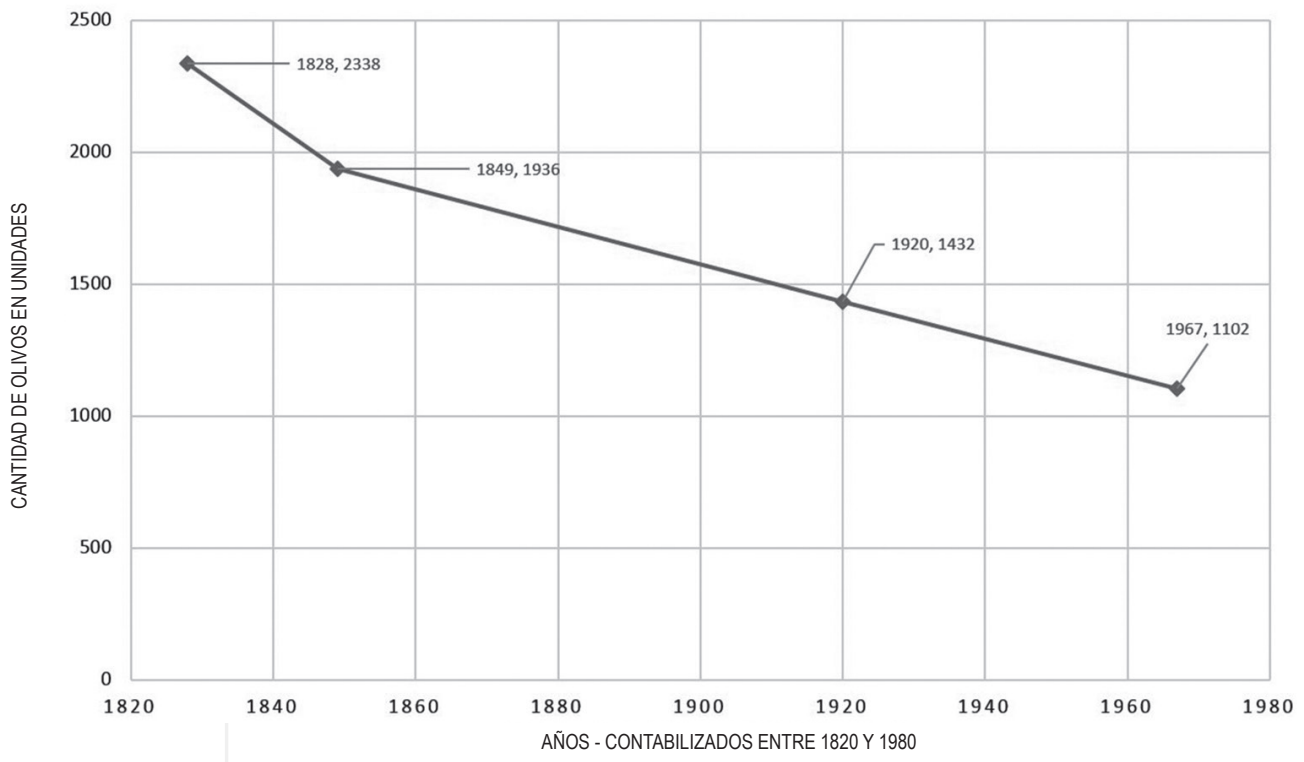

Figura 12. Decrecimiento de la cantidad de olivos durante 1828 y 1967

Elaboración propia
El inventario del año 1967 representa el punto más crítico en la transformación del bosque El Olivar. Este inventario se realizó doce años después de la declaración del bosque como zona monumental. Es a partir de esa fecha que se observa una tendencia inversa, ya que se inicia un proceso de recuperación del bosque de olivos que llevó a que durante los años 1967 y 2017, es decir, los últimos cincuenta años, se hayan recuperado un total de 572 olivos. 
Este proceso de recuperación del bosque coincide con la consolidación del paisaje conservado. Se evidencia que la búsqueda por la preservación del bosque El Olivar se traduce en la recuperación del número de olivos; sin embargo, el proceso de recuperación es lento, dado que, para recuperar la cantidad de olivos en el punto máximo histórico (los 2338 olivos contados en el año 1828), considerando que el ritmo de recuperación es constante y similar al de los últimos cincuenta años, se proyecta que se van a necesitar otros cincuenta años; es decir, que para recuperar el esplendor original del bosque de olivos se necesitan un total de cien años, contabilizados a partir del año 1967, tal y como se muestra en la figura 13.

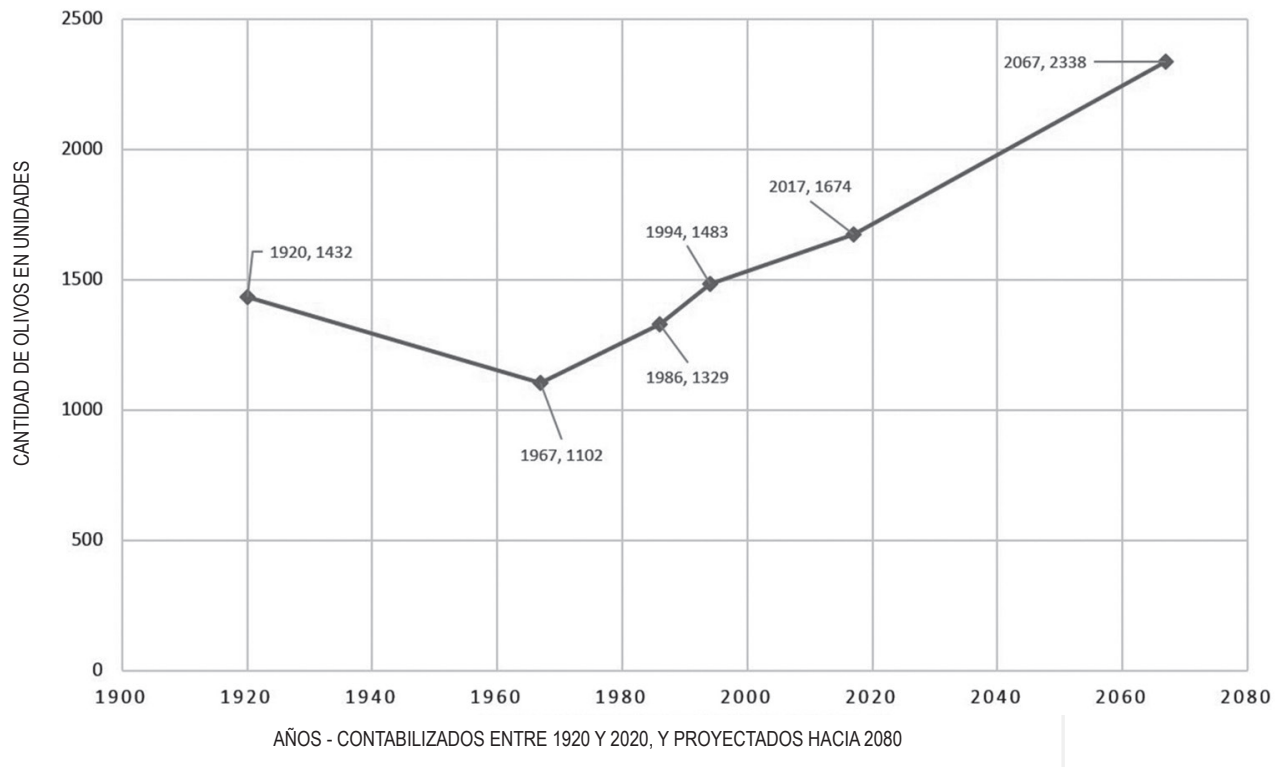

Sería pertinente decir que es mucho más costoso recuperar el sentido original de un paisaje que lo que toma alterarlo a través de la negligencia humana. Es de esperar una recuperación del bosque El Olivar, gracias a la normativa que promueve la preservación, así como a la mayor conciencia sobre el significado de este espacio y también debido a la puesta en funcionamiento de un sistema de riego que toma en cuenta las peculiaridades hídricas del olivo.

Figura 13.

Recuperación de la cantidad de olivos y proyección entre 2017-2067

Elaboración propia

\section{CONCLUSIONES}

El Olivar es un paisaje cultural de naturaleza cambiante que ha pasado por diversos períodos condicionados a las transformaciones que el hombre ha realizado en su uso a lo largo de la historia. Empezó siendo un paisaje sostenible por obra de los antiguos peruanos, luego a ser un espacio sembrado de olivos y cultivado por los colonizadores españoles, de ahí pasó a ser un espacio recreativo de una urbanización emblemática del crecimiento urbano de Lima y finalmente, a razón de todo este recorrido anterior, ha asumido un valor 
patrimonial y un aporte paisajístico para la comunidad, lo que permite su conservación sostenible.

Por lo expuesto, El Olivar es un libro abierto de infinitas posibilidades conforme a los valores reconocibles en él. Actualmente, es percibido simultáneamente como bosque o como parque, dependiendo del uso y de la percepción del usuario. También puede asumir otros significados, como paisaje campestre, patio para los niños, jardín para los vecinos, lugar de entrenamiento para deportistas o punto de atracción turística para visitantes de otros distritos de Lima y extranjeros. Tantas posibilidades son una fuente inagotable de oportunidades, pero también de conflictos, sobre todo cuando estos usos se superponen arbitrariamente. Hallar un equilibrio entre tantos valores y roles generados debe ser el punto crítico de una gestión integral de El Olivar.

El deterioro del bosque El Olivar y la pérdida de innumerables olivos se debió primeramente a la sustitución del rol original que caracteriza a dicho paisaje. Al cesar la actividad principal que forjó la aparición de este paisaje sobre el territorio, es decir, la producción agrícola de los olivos, su conservación se vuelve muy complicada, ya que las actividades que sobrevienen se implantan sin tomar en cuenta las características del componente biótico existente, como es el caso de sus cuidados específicos. Al incorporarse a la ciudad como parte de la nueva urbanización, el público reclamó al viejo bosque como un lugar de esparcimiento, ahí es donde el olivo perdió su preponderancia a favor de especies vegetales extrañas al lugar y de equipamientos intrusivos.

Hay que destacar la visión urbanística de Manuel Piqueras Cotolí por incorporar los elementos culturales autóctonos y las preexistencias territoriales al planeamiento de un nuevo núcleo residencial que daría origen a uno de los distritos más modernos de nuestra capital. Esta visión, basada en un renovador enfoque cultural y "mestizo", deudor de su época, rompe con el viejo damero de Pizarro que había guiado el crecimiento de la ciudad y establece un nuevo patrón orgánico que privilegia las experiencias espaciales y el disfrute de la naturaleza por sobre el estricto ordenamiento, patrón que posteriormente servirá de inspiración para diversas urbanizaciones limeñas.

Como consecuencia del cambio de uso, la degradación de El Olivar se vio acentuada por el riego desigual. Luego de 1920 hubo una introducción progresiva de pasto y de plantas ornamentales en todo el olivar a fin de conformar un lugar recreativo para disfrute de los vecinos de la urbanización. Como se ha indicado, estas especies consumen una mayor cantidad de agua y en más frecuencia que los olivos. Esto llevó a una saturación hídrica por décadas que resultó en un daño importante a la mayoría de los olivos; más del $40 \%$ se hallan enfermos y otros tantos se perdieron.

Esta gestión negligente del paisaje casi pone en peligro la integridad de un olivar de valor patrimonial excepcional. El problema viene siendo atajado gracias al sistema de riego tecnificado, realizado recientemente por las autoridades, junto a otras medidas como la poda y la fumigación, lo que indica que 
la conservación del bosque es una política ambiental permanente, con la visión de obtener resultados a mediano plazo en el poblamiento de nuevos olivos y un renovado aprovechamiento productivo de la especie, fuente por excelencia de biodiversidad.

Fue positivo el reconocimiento del valor histórico-cultural de El Olivar y su declaración como Monumento Nacional en 1959 a través de la Resolución Suprema n. ${ }^{\circ} 577$, ya que marca un punto de inflexión en la evolución del bosque. El análisis ha evidenciado que el inicio de estos esfuerzos normativos por la conservación de El Olivar ha tenido un efecto positivo en el incremento de árboles de olivo; sin embargo, este proceso de recuperación se ha dado lentamente, y es que dicha declaración fue más bien una aproximación superficial y efectista, sin un contenido normativo que gestione dicha monumentalidad, el cual tuvo que esperar varias décadas en ser plasmado.

De la normatividad relevante, se observan una serie de restricciones en uso, en los parámetros permisibles y en la magnitud de las intervenciones, las que pretenden mantener a El Olivar como un ente estático, ignorando la naturaleza dinámica del paisaje como evidencia evolutiva del territorio, así como el potencial particular del dicho lugar, habida cuenta, además, de que dichas restricciones no fueron siempre respetadas. La cantidad de modificaciones al Reglamento revela los enfoques particulares de las diversas gestiones municipales distritales y provinciales, en ausencia de una visión integral de El Olivar que permita la aplicación de criterios definidos de manera sostenida en el tiempo.

A esto se suma la multiplicidad burocrática, ya que estos dispositivos normativos transitan entre la municipalidad distrital, la metropolitana y el Ministerio de Cultura (antes era el INC), no siempre en beneficio del espacio. Recordemos, por ejemplo, que el Reglamento tomó más de diez años en ser aprobado, sin reparar en el deterioro sufrido por El Olivar en ese período. Finalmente, el interés del distrito en obtener la declaratoria de área de conservación ambiental es significativa, dado que marca una nueva pauta conceptual que valora el aspecto ambiental y sostenible del paisaje como base de los futuros esfuerzos de preservación.

Sobre el componente humano, se puede hablar de ciudadanía a partir de 1920, cuando se inicia la población de la nueva urbanización. Primeramente, los nuevos vecinos reclamaron al bosque como espacio recreativo particular, dicho cambio de uso motivó las intervenciones ya conocidas que ocasionaron un perjuicio al conjunto de olivos. Por otro lado, siempre han existido iniciativas ciudadanas que alzaron su voz en salvaguarda del bosque de olivos, desde la intervención de Luis Paz Soldán en la declaratoria monumental de 1959 hasta la presión pública de algunos vecinos durante la década de los noventa con el fin de evitar la vulneración espacial de El Olivar por parte de ciertos proyectos residenciales, lo que contribuyó a la esperada designación como zona monumental en 1998. 
En la actualidad, hay una mayor conciencia ciudadana de la importancia cultural y ambiental del bosque, que permite una implicancia positiva y una mayor aceptación de aquellas acciones realizadas en salvaguarda del bosque. Esto se aprecia en los cultivos recientes de aceitunas que involucran a los vecinos, que así comprenden cómo el carácter utilitario de los olivos definió al paisaje. El componente humano pasa de ser un mero observador a ser protagonista del proceso cultural.

Asimismo, plasmamos nuestra inquietud en las siguientes ideas y posibles líneas de acción que permitan restaurar el bosque a su estado óptimo:

- Debe restituirse la imagen original del bosque El Olivar, con el olivo como especie preponderante, subordinando el rol de parque al rol de bosque. Ambos roles pueden ser complementarios, a través del esparcimiento y la recreación pasiva para el público, pero en ningún caso el parque puede imponerse al bosque. Es posible lograr un equilibrio entre la función social de múltiples usos como parque y el valor ambiental del bosque en el contexto del distrito.

- Por lo mismo, debe revisarse la pertinencia de elementos extraños como la laguna o ciertos mobiliarios públicos, ponderando su valoración por parte de los usuarios del bosque. El sistema de riego tecnificado debe ser evaluado constantemente a fin de lograr resultados óptimos.

- Las especies ornamentales son permitidas, así como la introducción de césped de bajo consumo de agua; en ningún caso especie alguna puede poner en peligro la integridad o protagonismo de los olivos.

- Es conveniente una adecuada gestión paisajística y participativa que integre todas las políticas actuales, el marco normativo (local, nacional e internacional) y los actores (autoridades, especialistas, vecinos y visitantes) de manera que sean articuladas de manera integral y provechosa.

- Establecer metas de preservación y recuperación de los olivos a corto, mediano y largo plazo, con miras a los quinientos años del bosque (2060), con resultados tangibles y evaluables.

- Es válido tomar referentes externos de manejo provechoso de bosques en entornos urbanos, como Boulogne (París), Tiergarten (Berlín) o el Jardín Botánico de Medellín, a fin de incorporar dichas experiencias a la gestión local.

- Recuperar y promover la plena producción de los olivos, con fines de comercialización, ya que es el escenario más deseable de recuperación de la función original del bosque. La rentabilidad económica 
generada podría revertir como inversión en el bosque. Se podría obtener una certificación de dicho aceite para su mejor promoción.

- Es necesaria una reformulación consensuada del dispositivo normativo de El Olivar, a nivel distrital, provincial y nacional, de manera que permita una gestión dinámica y sostenida en el tiempo, más allá de los vaivenes políticos. Es importante incorporar una revisión crítica de todo lo realizado hasta el momento, como los incumplimientos de las normas, los reajustes en la zonificación y delimitación, revalorización de los usos públicos y compatibilidades, evaluar la capacidad de uso del espacio público y del futuro crecimiento inmobiliario, entre otras.

- A fin de eliminar las superposiciones normativas, delimitar las actuaciones de los agentes que intervienen, definir los criterios de intervención y unificar todo lo vigente, se deberá contar con un plan integral y multidisciplinario, así como su reglamento de aplicación, con un horizonte a varias décadas, evitando nuevas actualizaciones y precisiones engorrosas. Este plan será una herramienta valiosa para el desarrollo sostenible del bosque, ya que deberá incorporar criterios específicos del Ministerio del Ambiente.

- Se debe promover a El Olivar como espacio de participación ciudadana, mediante la comunicación fluida, democrática y pedagógica de las actuaciones sobre el bosque. Asimismo, motivar la participación vecinal a través de programas, concursos y actividades vivenciales.

- Se pueden integrar los espacios más relevantes del bosque como un museo de sitio vivencial del último entorno productivo virreinal y republicano en pleno corazón de la modernidad de San Isidro, a través de una puesta en valor conveniente y un guion interpretativo del lugar.

Finalmente, concluimos afirmando que el patrimonio debe ser la base de un ordenamiento territorial exitoso para un manejo coherente de las aspiraciones del presente y de la sostenibilidad para el disfrute futuro. La convivencia entre la producción agrícola, el disfrute paisajístico, la biodiversidad natural y la actividad recreativa es posible bajo una sabia gestión y tomando como base la imagen original del lugar. Es prioritario entender y respetar las preexistencias territoriales, así como gestionar el ecosistema entendiendo que el hombre no puede sacrificar las características intrínsecas de un paisaje en aras del simple disfrute estético y escenográfico del mismo, sino que más bien se debe lograr un punto de equilibrio entre los componentes cultural y natural, que garantice la continuidad del paisaje como un legítimo derecho ciudadano. Paradójicamente, esto cobra mayor importancia ante la presente pandemia que azota al mundo: ante el continuo confinamiento y la incertidumbre social, los paisajes y los espacios públicos cobran una importancia inusitada como medios de escape. Es necesario recuperar al bosque de olivos mediante nuevas 
formas de uso sostenible del espacio público, priorizando la vida y la salud de estos olivos, centenarios testigos de nuestra ciudad.

\section{REFERENCIAS}

Aristizabal, R. y Loaiza, C. (2017). Hacia una pedagogía del espacio público desde el enfoque de ciudad educadora en la Institución Educativa Héctor Abad Gómez (trabajo de grado). Universidad de San Buenaventura, Medellín, Colombia.

Arheidt, K. H. y Wieser, M. (1997). Lima - ayer y hoy: Fotos frente a frente. Rastatt, Alemania: SMR-Druck.

Ascencios, D. y Peña, M. (2014). Diagnóstico, diseño y evaluación económica del sistema de riego por aspersión del bosque El Olivar. Anales Científicos (75), 202-209. Recuperado de http://revistas.lamolina.edu.pe/index.php/ acu/article/view/951

Biblioteca Nacional del Perú. (1940). San Isidro, ciudad jardín [Archivo de video]. Recuperado de https://www.youtube.com/watch?v=CQEIXiWsccU

Briceño-Avila, M. (2018). Paisaje urbano y espacio público como expresión de la vida cotidiana. Revista de Arquitectura (Bogotá), 20(2), 10-19. doi: http: //dx.doi. org/10.14718/RevArq.2018.20.2.1562

Conferencia Internacional sobre Conservación. (2000). Carta de Cracovia. Recuperado de http://ciat.aq.upm.es/wp-content/uploads/2016/01/CC_2000.pdf

Consejo de Europa. (2000). Convenio Europeo del Paisaje. Recuperado de https:/l rm.coe.int/16802f3fbd/ELC-spanish.pdf

Coronado, J. (2018). La urbanización al sureste de Lima a lo largo de la avenida Leguía y las malas prácticas de los desarrolladores inmobiliarios entre los años 1919 y 1930. Anuario de Espacios Urbanos, Historia, Cultura y Diseño (25), 186-187.

Dargent, E. (2018). Olivos y olivas en la historia del Perú. Universidad Ricardo Palma. Recuperado de https://www.urp.edu.pe/pdf/id/20929/n/libro-olivos-y-olivas. pdf

Dolorier, C. (2013). Cronología, organización social, especialización laboral y género definidos como producto del análisis de los contextos funerarios registrados en los "diarios de campo" de Huallamarca, años de 1958 y 1960 (tesis de grado). Universidad Nacional Mayor de San Marcos, Lima, Perú. Recuperada de https://cybertesis.unmsm.edu.pe/handle/20.500.12672/4772

El Olivar: ubican árbol de olivo plantado por San Martín de Porres. (12 de septiembre del 2017). El Comercio. Recuperado de https://elcomercio.pe/lima/ patrimonio/olivar-ubican-arbol-olivo-plantado-san-martin-porres-noticia457449-noticia/ 
Etter, A. (1991). Introducción a la ecología del paisaje: Un marco de integración para los levantamientos ecológicos. Researchgate. Recuperado de https://www. researchgate.net/publication/268147634_Introduccion_a_la_Ecologia_ del_Paisaje

García, A. et al. (1989). Reglamento de Conservación; Revalorización, Zonificación y Edificación para la Zona Monumental del Bosque de Olivos del Distrito de San Isidro. Lima, Perú: Municipalidad de San Isidro.

Gehl, J. (2014). Ciudades para la gente. Buenos Aires: Ediciones Infinito.

López, R. (Ed.). (2011). Andalucía y América, patrimonio artístico. Granada: Editorial Atrio.

Ludeña, W. (2008). Paisaje y paisajismo peruano. Apuntes para una historia crítica. Textos-arte, (4), pp. 59-84.

Ludeña, W. (2009). Urbanismo dixit. Inquisiciones. Quito: Organización Latinoamericana y del Caribe de Centros Históricos (OLACCHI).

Lugo, P. (2019). El paisaje urbano. Academia.edu. Recuperado de https://www.aca demia.edu/1169181/EL_PAISAJE_URBANO

Maderuelo, J. (2010). Paisaje y patrimonio. Madrid: Abada Editores.

Mariani, L. (1857).Plano Topográfico de losAlrededores de Lima. Recuperado de https:// es.wikipedia.org/wiki/Archivo:Plano_Topografico_De_Los_Alrededores _De_Lima.jpg

Martuccelli, E. (2006). Lima, capital de la Patria Nueva: el doble centenario de la independencia en el Perú. Apuntes, (19), 256-273. Recuperado de https:// revistas.javeriana.edu.co/index.php/revApuntesArg/article/view/9036

Mascco, D. (2018). Evaluación ambiental para la planificación del ecoturismo, del monumento nacional bosque El Olivar, San Isidro, Lima, 2017 (tesis de grado). Universidad Nacional Federico Villarreal, Lima, Perú. Recuperado de http://repositorio.unfv.edu.pe/handle/UNFV/2770

Mata, R. (2006). Un concepto de paisaje para la gestión sostenible del territorio. Cátedra San Vicente. Recuperado de https://catedrasanvicente.files.word press.com/2011/03/un-concepto-de-paisaje-para-la-gestion-sostenibledel-territorio_mata-olmo.pdf

Ministerio de Cultura y Deporte. (2012). Plan Nacional de Paisaje Cultural. Cultura y Deporte. Recuperado de http://www.culturaydeporte.gob.es/planes-nacio nales/planes-nacionales/paisaje-cultural/definicion.html

Mundial. (7 de abril de 1922). (99), p. 37.

Municipalidad de San Isidro. (2014a). Memoria institucional. Recuperado de http://www. munisanisidro.gob.pe/transparencia/tema02/Memoria_Institucional_2014.pdf

MunicipalidaddeSan Isidro.(2014b). Nuestras raíces: San Isidroy su historia. Recuperado de https://issuu.com/prensasanisidro/docs/libro-historia-de-san-isidro 
Municipalidad de San Isidro. (2018). Iniciamos cosecha de aceitunas de árboles del bosque El Olivar. Recuperado de http://msi.gob.pe/portal/2018/04/23/ iniciamos-cosecha-de-aceitunas-de-arboles-del-bosque-el-olivar/

ONU. (2015). Objetivos del desarrollo sostenible. Recuperado de https://www.un.org/ sustainabledevelopment/es/objetivos-de-desarrollo-sostenible/

Orrego, J. (8 de junio del 2008). La hacienda San Isidro [mensaje en un blog]. Recuperadode http://blog.pucp.edu.pe/blog/juanluisorrego/2008/06/08/la-hacien da-san-isidro/

Orrego, J. (2013). Lima 1. El corazón de la ciudad. Lima: Aguilar.

Priego, C. (2002). Beneficios del arbolado urbano (ensayo de doctorado). Instituto de Estudios Sociales Avanzados, Córdoba, España. Recuperado de https://digital.csic.es/bitstream/10261/24578/1/Beneficios\%20del\%20 arbolado\%20urbano.pdf

Rivera, J. (2010). Paisaje y Patrimonio. Academia.edu. Recuperado de https://www. academia.edu/10794242/Paisaje_y_patrimonio

Ruiz, C. etal. (2018). Olivares vivos. La biodiversidad como valor añadido en agricultura. Desde los servicios ecosistémicos a la diferenciación comercial (proyecto de investigación). Estación Experimental de Zonas Áridas, Almería, España. Recuperado de https://digital.csic.es/bitstream/10261/215198/1/ olivivo.pdf

Silva, L. (13 de abril del 2013). Riego tecnificado en El Olivar de San Isidro ahorrará el $70 \%$ de agua. El Comercio. Recuperado de https://elcomercio.pe/sociedad/ lima/riego-tecnificado-olivar-san-isidro-ahorrara-70-agua-noticia-1563289/

Silva, P. (1993). Percepción del paisaje. Aisthesis, (25-26). Recuperado de http:/l estetica.uc.cl/images/stories/Aisthesis1/Aisthesis2526/percepcin_del_ paisaje_patricio_silva_jeria.pdf

UNESCO. (1972). Convención sobre la Protección del Patrimonio Mundial Cultural y Natural. Recuperado de http://portal.unesco.org/es/ev.php-URL_ ID=13055\&URL_DO=DO_TOPIC\&URL_SECTION=201.html

Valdez, E. (2017). La apreciación estética del paisaje: naturaleza, artificio y símbolo (tesis de doctorado). Universidad Politécnica de Madrid, Madrid, España. doi: https://doi.org/10.20868/UPM.thesis.48452

Vargas, J. (2017). El olivo monumental plantado por San Martín de Porres. Cultura, (31), 59-65. doi: https://doi.org/10.24265/cultura.2017.v31.03

Vera y Moreno Consultores. (2006). Plan Integral del Bosque el Olivar.

Villamón,J.(2016). ElOlivardeSanIsidro. Ejemplopaisajísticode Lima. Arquitextos, (31), 69-78. Recuperado de https://revistas.urp.edu.pe/index.php/Arquitextos/arti cle/view/2089 